\title{
Understanding the lived experience of British non-offending paedophiles.
}

\begin{tabular}{|r|l|}
\hline Journal: & Journal of Forensic Practice \\
\hline Manuscript ID & JFP-10-2019-0046.R1 \\
\hline Manuscript Type: & Research Paper \\
\hline Keywords: & $\begin{array}{l}\text { paedophilia, minor attraction, child sexual abuse, prevention, sexual } \\
\text { offending, sexuality }\end{array}$ \\
\hline
\end{tabular}

SCHOLARONE $^{\mathrm{m}}$
Manuscripts $^{\text {Manusion }}$ 
MANUSCRIPT DETAILS

TITLE: Understanding the lived experience of British non-offending paedophiles.

\begin{abstract}
:
Purpose

Research into paedophilia mainly uses offender samples, thus little is understood about nonoffending paedophiles. The limited body of research has been conducted in North America or Europe, whose health and legal systems differ to those in the UK. Using semi-structured interviews, the present study explored the experience of three non-offending British paedophilic males.
\end{abstract}

Design

The interview discussed their paedophilia, refraining from offending, and perspectives on treatment initiatives. Data were analysed using Interpretative Phenomenological Analysis.

Results

Three superordinate themes emerged; â€ paedophilia as more than a sexualityâ $€^{\mathrm{TM}}$, â€ acceptance leads to managementâ $€^{\mathrm{TM}}$, and â $€^{\sim}$ barriers to supportâ $€^{\mathrm{Tm}}$. These encapsulated how paedophilia was understood, how accepting oneâ $€^{\mathrm{TM}} \mathrm{s}$ sexual attraction is tantamount to well-being and the various obstacles to providing support were discussed.

Acknowledging the sampling considerations (size and recruitment), the results implicate future research into paedophilia. The onset of paedophilia was associated chronologically with typical sexual attraction, not the result of sexual abuse as some theories suggest, and the tenets of attraction to children extending beyond sexual desire were highlighted. Practically, the results influence future research into the area, and highlight the dearth in our understanding of diverse behavioural management techniques (i.e. computerised images of children, human-like dolls).

Practically, the results influence current treatment initiatives in the UK, and highlights the dearth in our understanding of diverse behavioural management techniques (i.e. computerised images of children, human-like dolls).

CUST_SOCIAL_IMPLICATIONS_(LIMIT_100_WORDS) :No data available.

Originality

This paper presents novel insight into the aspects of paedophilia, excluding offensive behaviour, and highlights the need for affordable, UK-based services targeted towards people with a paedophilic attraction, to manage child sexual abuse preventatively, not reactively. 


\begin{abstract}
Purpose

Research into paedophilia mainly uses offender samples, thus little is understood about nonoffending paedophiles. The limited body of research has been conducted in North America or Europe, whose health and legal systems differ to those in the UK. Using semi-structured interviews, the present study explored the experience of three non-offending British paedophilic males.

Design
\end{abstract}

The interview discussed their paedophilia, refraining from offending, and perspectives on treatment initiatives. Data were analysed using Interpretative Phenomenological Analysis.

\title{
Results
}

Three superordinate themes emerged; 'paedophilia as more than a sexuality', 'acceptance leads to management', and 'barriers to support'. These encapsulated how paedophilia was understood, how accepting one's sexual attraction is tantamount to well-being and the various obstacles to providing support were discussed.

\section{Limitations/Implications}

Acknowledging the sampling considerations (size and recruitment), the results implicate research into paedophilia. The onset of paedophilia was associated chronologically with typical sexual attraction, not the result of sexual abuse as some theories suggest, and the tenets of attraction to children extending beyond sexual desire were highlighted. Practically, the results influence future research into the area, and highlight the dearth in our understanding of diverse behavioural management techniques (i.e. computerised images of children, human-like dolls).

\section{Originality}

This paper presents novel insight into the aspects of paedophilia, excluding offensive behaviour, and highlights the need for affordable, UK-based services targeted towards people with a paedophilic attraction, to manage child sexual abuse preventatively, not reactively.

Keywords: paedophilia, minor attraction, prevention, child sexual abuse, sexual offending, sexuality

Paper Type: Research Paper 


\section{Introduction}

Sexual preference for children accounts for approximately a quarter to a half of child molestation offences (Seto, 2012), suggesting that many child sex offenders are not paedophilic in their preference, and vice versa. Recent research identified distinctions between paedophilic offenders, non-paedophilic offenders and paedophilic non-offenders on measures of personality and self-reported levels of childhood abuse (Gerwinn et al, 2018), evidencing that these groups should not be evaluated interchangeably. Analogous to males and females admitting sexual arousal by rape fantasies, without wanting to rape or be raped, a person's sexual fantasies towards children may not be necessarily predictive of sexual behaviour (Berlin, 2014). Qualitative interviews with paedophilic males, imprisoned for sexual offences against children, revealed the internal battle that they faced with their sexuality and the assumed stability of paedophilia (Walton \& Duff, 2017). Results from forensic populations of paedophiles are valuable, but may be confounded by sex offender treatment programs, and traits acquired in the prison or hospital environment (Walton \& Duff, 2017).

\section{Non-forensic samples}

Cantor and McPhail (2016) reviewed emerging literature on non-offending paedophiles, detailing how stigmatisation is not limited to child sex offenders. Houtepen, Sijtsema, and Bogaerts (2016) interviewed non-imprisoned paedophiles, a subset of whom disclosed prior offences. Analysis revealed most offences were committed during a time of heightened sexual preoccupation, and some justified offences against children by expressing how behaviour was motivated by love not lust (Houtepen et al, 2016). Freimond (2013) 
interviewed males referred to as 'minor attracted', showing how real or perceived stigma was the cause of much stress, and often hindered people seeking professional help. Stigmatisation occurred when people disclosed their minor attraction, and peoples' reactions to this were spread across a wide spectrum ranging from wholly accepting, to entirely discriminatory (Freimond, 2013; Goode, 2010). Due to the diversity of reactions, a large percentage of this community resort to secrecy and withdrawal from social relationships; admitting a lack of authenticity and honesty within their friendships (Houtepen et al, 2016) and social isolation (Goode, 2010).

A sample of non-offending and ex-offending paedophiles from the Netherlands and Belgium reported managing their feelings by seeking professional help, advice from friends, or peer support via online networks (Houtepen et al, 2016). Amongst their non-offending sample, sexual desire was managed by sexual contact with adults, adult pornography, and fantasy during masturbation. Walker (in press) recruited self-identified non-offending paedophiles from North America, and identified similar adaptive management strategies at outlined by Houtepen et al (2016), in addition to maladaptive techniques such as drug and alcohol use, and suicidal ideation. Participants in Walker's (in press) sample reported the primary motivations to suppress the behavioural urges were knowing the harm it may bring to a child and the potential legal consequences for themselves. Urges were managed diversely; some abstained from contact with children entirely, others surrounded themselves with minors as an attempt at desensitisation; many viewed adult pornography, others viewed images and videos of children depicted in mainstream media, or computer generated images of children popularised by Japanese culture (Walker, in press). 


\section{Services}

Initiatives have aimed to offer interventions for paedophiles, who have either offended and wish to refrain, or those who are offence-free. Prevention Project Dunkelfeld (PPD), a government-funded German initiative launched in 2005 , was the first methodical attempt to combat child sexual abuse by intervening before an offence has taken place. The program focusses on cognitive-behavioural therapy, emphasising alternatives to offending, as they believe one cannot be held accountable for paedophilia, but for the actions which may ensue (Beier et al, 2009). Preliminary results indicated improvements in emotional state and sexual self-regulation, and a reduction in offense-supportive cognitions (Beier et al, 2015).

Additional research is necessary however, as many of the sample self-reported continued online offending during treatment (Beier et al, 2015). Despite these services, seeking therapy as a paedophile is rare (Cacciatori, 2017). This is due to several barriers, such as pessimistic expectations of therapy, fear of being exposed, misunderstood, criminally prosecuted, and negative evaluation from the therapist (Cacciatori, 2017).

The majority of research into non-clinical paedophiles has been conducted in countries whose health and legal systems differ to those in the UK (Freimond, 2013; Beier et al, 2015; Houtepen et al, 2016; Cacciatori, 2017; Walker, in press), thus it is of clinical and societal benefit to explore the experience of British non-offending paedophiles. Understanding the daily lives and perspectives of non-offenders experiencing paedophilia in the UK could provide insight on current initiatives. As many aforementioned studies include previous offenders (Houtepen et al, 2016; Walker, in press), the current study aims to understand British paedophiles who state they have never offended, exploring their perspective of sexuality, management techniques implemented to avoid offending, and opinions towards UK health services. 


\section{Methodology}

\section{The research project was approved by the Medical School Ethics Committee at a}

Russell Group university. A semi-structured interview was designed to address the participants' conceptualisation of paedophilia, their management strategies, and their perspectives on services. Qualitative methodology is favourable in researching this, as interviews permit for idiographic and diverse discussion of a phenomena (Walker, in press). The interview data were analysed using Interpretative Phenomenological Analysis (IPA; Smith, Jarman \& Osborn, 1999) which is the preferred approach over others as it has proven effective in analysing subjects that are "complex, ambiguous and emotionally laden" (Smith \& Osborn, 2015, p.41).

\section{Participants}

Smith and Osborn (2008) suggest a sample size of three to six is sufficient for projects employing IPA. The inclusion criteria for participation were British males over the age of 18, who had a self-identified attraction to minors (pre and post pubertal, under 16 years of age) and declared no history of contact or non-contact offences. For participant demographics, see Table 1.

[Insert Table 1 here]

\section{Procedure}


Advertisements requesting participation were distributed on Twitter, 'Virtuous Pedophiles' (www.virped.org), and a prevention charity's website (www.stopso.org.uk). Participants received an information sheet describing the study aims and provided informed consent. Interviews were conducted using online calling software or over a mobile phone and were recorded using the researcher's own recording device. Each participant was informed in writing and verbally that disclosing illegal activity would result in interview termination and local authorities being informed. Following the interview, participants were debriefed, signposted to relevant organisations offering support, and informed they had seven days to withdraw their data. The interviews were transcribed by the researcher, ensuring any details pertaining to the identity of the participants were omitted.

\section{Data Analysis}

IPA (Smith, Jarman \& Osborn, 1999) explores a person's unique perception of an experience. The process is a dynamic exchange between researcher and participant, whereby the researcher must employ their own sense-making of the participant's experiences, whilst acknowledging their own assumptions and concepts (Smith \& Osborn, 2008). IPA is an appropriate framework to address this topic as it exempts the researcher from the rigidity of existing theoretical preconceptions (Smith \& Osborn, 2015), which are lacking amongst the literature on non-offending paedophiles.

In the present study, IPA, as outlined by Smith, Flowers and Larkin (2012), was conducted following a six-step procedure. 1) Reading the transcript multiple times to engage with the text. 2) Each transcript was formatted to table form, with one column on each side of the text, and initial comments were made in the left hand column whilst listening to the transcript. Notes were taken based on the participant's language use, emphasis on certain words or 
phrases, and other characteristics of the person's expression. 3) Identifying budding themes from the text, written in the right hand column. These initial themes developed after reviewing the initial notes in the left hand column, and conceptualising them to apply to the person's experience. These initial themes were then used to form superordinate themes. 4) Superordinate themes were identified using the processes of abstraction (clustering similar initial themes to form broader concepts), and numeration (noting the frequency in which a theme or concept appeared, Cacciatori, 2017). 5) Repeating the above processes with subsequent transcripts. 6) Identifying co-occurring themes across the interviews.

\author{
Analysis \\ Ensuring credibility within qualitative research depends upon the trustworthiness, \\ consistency, and triangulation of the data (Noble \& Smith, 2015). The researcher kept \\ reflective notes to ensure trustworthiness in their account, enabling them to track progression, \\ note biases that arose, and reflect upon any challenges (Morse, Barrett, Mayan, Olson \& \\ Spiers 2002). To maintain trustworthiness of participants' accounts, the researcher verbally \\ summarised the participant's reflections, obtaining respondent validation (Long \& Johnson, \\ 2000). After each interview, the researcher listened to the recording to identify any \\ adjustments which could be made to the communication style, and left sufficient time \\ between interviews to ensure clarity in approaching the next participant. Consistency was \\ maintained by keeping a clear audit trail of the research procedure, including changes to \\ protocol and archiving transcripts and any evidence of communication with external parties \\ (Smith et al, 2012). Triangulation in qualitative research contributes to the reliability and \\ validity of the research, by incorporating input from multiple sources (Carter et al, 2014). To
}


achieve data triangulation, participants were recruited from three distinct settings, increasing the diversity of the findings. In addition, to examine the reliability of meaning that was identified, the second author independently analysed one interview to allow for comparison between authors at the superordinate theme level of analysis. Any areas of dissimilarity were discussed and agreement was reached through reference back to the original material.

\section{Themes}

Three superordinate themes were identified: 'Paedophilia as more than sexuality', 'Acceptance leads to management', and 'Barriers to support'. For the sake of brevity, participant extracts have been condensed and participants' breaks in speech are denoted by the following: [...]. For the full list of themes and subthemes see table 2 .

\section{[Insert Table 2 here]}

\section{1) Paedophilia as more than sexuality}

This theme encapsulates how paedophilia was conceptualised by the participants. The subtheme 'Sensuality and sociality' reflects how the feelings participants had toward children were not exclusively sexual, consisting of romantic and sensual elements, which sometimes took priority over sexual desire. $\mathrm{P} 3$, who was attracted to female children and adults, reported fantasising about "kissing, cuddling, touching" children, as opposed to "the animalistic urge" for sexual intercourse and achieving "orgasm" with adult women. P3 applied the term "animalistic urge" to children, but distinguished the meaning of this between children versus adult women. His reference to the personality characteristics that children possess also reflected a social affiliation to children. 


\begin{abstract}
“when I say 'animalistic urges' I don’t mean, sort of, pouncing or preying on a child, I mean $[\ldots]$ worshiping them, being in physical contact"

“Cause $[\ldots]$ I find $[\ldots]$ girls in particular more so-well they've never smoked, never drunk alcohol, never taken drugs [...] they tend to be happier, simplistic, nonjudgmental, we lost a lot when we grow up I think [...] and it's that innocence I find, draws me"
\end{abstract}

This distinction posed a struggle for P1, who identified stronger romantic than sexual feelings about older male children. Managing these feelings was harder than the sexual aspect for P1, particularly due to his exclusive paedophilic attraction. He also admits that his mental health difficulties may be worsened by the "inability to get romantic and sensual aspects".

\author{
"the sexual bit is, easy, easy enough to manage [...] but the more difficult bit to sort \\ of, deal with is the $[\ldots]$ romantic and sensual bit, $[\ldots]$ you can have sexual \\ gratification in other ways, it's hard to fulfil the romantic and sensual bit $[\ldots]$ you \\ can't really get that".
}

Relatedly, the next subtheme represents the emphasis made by all participants on the division between their preference and their behaviour. 'These are my feelings, not my actions' contains material expressed by the participants as a result of the public assumption that 'paedophile' and 'child abuser' are interchangeable. P2 stated, 'I'm a paedophile, I'm attracted to children, I'm not a sexual offender" and compared the misconception to "saying [...], 'heterosexuals are rapists'". The participants agreed that separation of behaviour from 
feelings was necessary in order to protect children, "I think you need to learn healthy ways to control it so you can be a functioning member of society" (P2) and that the management of feelings was separate to the sexual feelings, as P3 stated, “people just don't get that you can have this attraction and deal with it in a way that's not harmful to kids or to the individual". The media was held accountable for this misconception, and participants expressed how reporters should "stop using the word 'paedophile' for every, single, child molester" (P1). Due to the media's misconception of all paedophiles as "people like the 'Jimmy Savilles", this led P2 to adopt a self-fulfilling prophecy whereby offending is an inevitable conclusion.

"you see in the media [...] the people that act on these things they are rightfully monsters, but because I've had the same, uh, attractions, I assumed myself to also be part of that monster I was like [...] 'oh god I'm just as bad as them cause I've always felt the same way'",

\section{2) Acceptance leads to management}

The second theme pertained to participants' management of their feelings, in order to avoid offending. The first subtheme, 'repression is maladaptive', reflects how accepting paedophilia was productive to their management. For all participants, paedophilia was accepted as permanent, and two males named it as their primary sexuality, reporting no desire to change this. These participants recognised that repressing their sexuality led to negative consequences, and was counter-productive to their coping styles.

"I think repressing them and trying not to have them is just likely to end up far worse than just acknowledging them and accepting them and learning how to deal with them 
healthily and safely [...] rather than just trying to [...] push them to the back of your brain and ignore them $[\ldots]$ never ends up well in the end" (P1).

“I think I'm more comfortable with it [...] I realise it's a serious thing that I've got and it's a general orientation not just a bit of a laugh $[\ldots]$ now that I've learnt to embrace all my sexual interests, I'm more comfortable with myself [...] I've given up trying to fight them [...] I think if you fight them you're at a losing battle" (P3).

$\mathrm{P} 2$ referred to paedophilia as his disorder, not sexuality, and admitted adopted maladaptive coping strategies such as substance misuse and suicidal ideation. He encapsulates this subtheme because he stated that understanding the cause of his paedophilia would improve his well-being via acceptance "I kind of wish I had been abused as a child because then I'd understand where the feelings came from, why they're there and I could deal with them and maybe get past them". Accepting this sexuality as opposed to repressing or pathologizing it represented an adaptive approach within the current sample, as P1 and P3 did not report engaging in any self-injurious behaviour.

Related to attitudes towards UK services, participants expressed that services were incorrectly focused on repressing instead of accepting one's sexuality. P1 used a phone service provided by 'Stop It! Now UK' and stated, 'they're quite anti, anti-paedophile [...] they're very anti-fantasy anti-thoughts $[\ldots]$ you've got to suppress it and repress it $[\ldots]$ it's not helpful for me at all”. P2 corroborated this, after experiencing suicidal ideation he phoned the same helpline stating they just advised him, "to stop thinking about it". Repression was seen as damaging to one's therapeutic progression by P3, "Yes, also for a lot of us a big 
barrier is being honest with ourselves $[\ldots]$ it's the realisation in any sort of therapy program that people are in denial".

Motivations to avoid sexual contact with a child were referenced in the second subtheme, as there emerged an apparent 'hierarchy of consequences'. For two participants in the sample, avoiding harm to a child took priority, with P1 stating the main motivator to avoid offending was the inherent nature of a child, "um, for me it's just they're kids" stating he would "never ever, ever put a child through that". P2 reiterated this, stating "I would not be able to live with myself if I did it”. For these participants avoiding harm to a child was of higher concern than protecting themselves, as P2 disregarded the legal ramifications by stating, "for me the legality...doesn't matter at all, even if it were legal, it would still be immoral [...] it would still be completely wrong to do". P3 reported remaining offence-free in fear of the legal ramifications, stating "given the chance with zero change of getting caught $[\ldots]$ I think pretty much all of us would" offend. However, data from all three participants in the sample suggests equal weighting to the personal and child-specific consequences, as P2 noted a "fear of exposure" in addition to the guilt, and P3 expanded on his views, stating he and others would engage in offending behaviour if they could ensure no legal consequences and "no harm to the child", as seeing a child in pain would harm him.

\section{3) Barriers to support}

This theme encompasses the participants' reflections on services and initiatives in the UK, and how they are inadequate in supporting paedophiles due to several obstacles. This theme consists of the following subthemes; inaccessibility and distrust of professionals. 
The subtheme 'inaccessibility' reflects factors which render support difficult to pursue. Participants identified two prominent barriers when accessing services in the UK; awareness and finance. P2, who has received therapeutic intervention from 'StopSO' emphasised the difficulty he experienced in finding it, "I spent a lot of time trying to search for them but I didn't find them". Lack of awareness was reiterated by P3 who stated "there's nowhere I could go". The financial ramifications contributed to the inaccessibility of services, as P1 admitted therapy may have benefitted him but, "the cost just made it impossible for [him] to consider", and P2 ceased therapeutic intervention due to the cost, "I found my therapist through 'StopSO' which is, which was helpful, uhm problem is I can't afford to go back to her". Commenting on both barriers to services, P1 remarks that he would've pursued intervention in his youth "if [he] knew it existed and [...] the cost was subsidised".

The second subtheme encapsulates a 'distrust of professionals'. Amongst the participants there was the perception that individuals are unqualified to adequately help manage paedophilia. For P1 this was evident in his opinions on the National Health Service, stating how “A, the mental health services are not great in general and B I don't think they're equipped to deal with, deal with some of this", leaving him perceiving a "lack of people out there that have the knowledge to actually help you". P3 expressed doubt towards the capacity of health professionals as a result of their non-paedophilia. He stated, "really I don't think there's anything they could do [...] they wouldn't have any understanding and their personal prejudices and intolerance if you like would prevent them giving me any advice cause they're not like it themselves".

Professionals were seen as untrustworthy concerning mandatory reporting. Comments were made by all three participants regarding mandatory reporting in the UK, and there was the 
perception that professionals report paedophiles, without just cause. P1 stated, "It's not very clear when someone's actually required to report”. He implied many non-offending paedophiles are deterred from seeking help because of the fear of being misunderstood, "well if someone's misinterpreted [...] blow it out of proportion it could...spiral out of control". P2 reflected on the fear of "knowing that this person could actually ruin my life", and P3 extended this negative attitude towards professionals, stating how their professional image prioritised helping non-offending paedophiles, "there's a possibility of being reported to police or CSA or whatever, for no good reason [...] cause they look for crimes [...] they'd be looking for reasons to report me as somebody who's a risk to kids...to make themselves look good". All participants agreed the legislation surrounding mandatory reporting should be transparent, and people should only be reported if they report illegal activity.

\section{Discussion}

Employing IPA, the present study investigated the experiences of three British males with paedophilic preference, who self-identify as non-offending. The research aimed to detail "the perceptions and understandings of this particular group rather than prematurely make more general claims" (emphasis added, p.55, Smith \& Osborn, 2008) and the qualitative data yielded has highlighted important areas for future research focus.

\section{Findings}


Consistent with extant literature on both non-offending and offending paedophiles, paedophilia was viewed as unchangeable by the participants (Seto, 2012; Walton \& Duff, 2017). The participants also identified feeling stigmatised by the media, for interchanging the terms 'paedophile' and 'child sex offender'. Confusing the terminology may not only detrimental to mental health (Hatzenbuehler, 2009), but adopting tenets of labelling theory (Becker, 1963), it can be argued that identifying someone as criminal may lead that person to fulfil such expectations. Research with a mixed sample of paedophiles revealed intense stigmatization predicted negative emotional and cognitive functioning, interpersonal difficulties, and lower motivation to seek help, and researchers hypothesized that these effects are clinically similar to risk factors for child sexual abuse perpetration (Jahnke, Schmidt, Geradt, \& Hoyer, 2015).

Results emerged from this sample regarding attraction to children, as the participants differentiated their attraction across sexual, social, and romantic domains. Previous research has found similar results amongst both offending and non-offending paedophiles (Walton, 2013; Houtepen et al, 2016; Walker, in press). Walton (2013) notes emotional identification with a child is regarded as an offence-supportive cognition (Finkelhor, 1984), however social interaction with children has been a preventative strategy in other samples (Houtepen et al, 2016), suggesting a gap in our understanding of intimate and social attraction to children, as popular behavioural modification techniques only seek to alter a sexual preference for children (Müller et al, 2014).

Both the current sample and offending counterparts agree avoidance is maladaptive and repression may be a risk factor for abuse perpetration (Blagden et al, 2017). In an age of such accessible internet content, those of certain sexual paraphilias may turn to virtual 
communities to feel accepted by like-minded individuals. Rosenmann and Safir (2006) argue this causes validation of unconventional or illegal desires and the exchanging of sexual scripts and fantasies, promoting what they refer to as 'paraphilic empowerment'. These fears corroborate research on the function of sexual fantasy and fantasy rehearsal and the role they play in reinforcing paedophilic sexual offenders to abuse children (Gee, Ward, Eccleston, 2003). Sheldon and Howitt (2010) however, examined the difference between rehearsal of a crime and sexual fantasies involving a child, and contrary to expectation, found a lower frequency of child sexual fantasies amongst paedophilic contact offenders than internet offenders, calling for further investigation into the function of fantasy specifically for nonoffending paedophiles. Understanding fantasy specific to non-offenders may affect future legislation on animated or computer generated sexualised imagery of children, both of which are illegal in the UK (Criminal Justice and Public Order Act, 1994, 2018).

Despite services such as 'Stop It! Now UK' and 'StopSO', participants reflected on the lack of signposting. Imprisoned paedophilic offenders expressed similar feelings and were unaware of available initiatives upon release (Walton, 2013). In Germany, a media campaign which openly advertised Prevention Project Dunkelfeld (PDD), was successful in recruiting those attracted to children from all over Germany (Beier et al, 2009). That campaign suggests a potential strategy could be employed in the UK, as only $8 \%$ of the $85 \%$ of self-referrals made to 'StopSO' in 2016 were non-offending paedophiles (Grayson, 2016). Financial implications were also discussed, hinting this prevented the current sample from engaging in therapy, thus future research is warranted to determine if this is reflected amongst the majority of British non-criminal paedophiles as a group. 
The present sample expressed a distrust of professionals, and some of the concerns raised were based on perceived, not real, experience. Embedded within this distrust were concerns of reporting and professional prejudice. Despite literature indicating a decline in reports of child abuse suspicions, the perception of prejudice may reflect reality as a professional's characteristics, employment duration, and beliefs about confidentiality have been shown to affect reporting rates (Bunting, Lazenbatt \& Wallace, 2010). Additionally, research conducted in Germany revealed $95 \%$ of psychotherapists stated they would not work with paedophiles, largely motivated by negative attitudes towards this group (Stiels-Glenn, 2010). Whilst removing mandatory reporting in the UK is unlikely, clearer legislation on reporting, and mandated training programmes to tackle stigmatization are plausible future directions in providing adequate support for paedophiles.

The most common form of treatment employed to tackle child sex offences is prison programmes to be administered post-offence (Gilbert \& Focquaert, 2015), yet current figures indicate law enforcement agencies are not capable of managing the rising number of such offences (Grayson, 2016). Thus, primary prevention is the logical focus for both the protection of children and the well-being of those attracted to them (Levine \& Dandamudi, 2016). However, before any model can be created or implemented, Beier et al (2009) cite a general societal acceptance of prevention work is necessary. Responsiblity may partially rest on the media presenting paedophiles with the correct terminology; research shows compassionate presentations of young, non-offending paedophiles can reduce the stigma amongst the public, encouraging more supportive attitudes (Theaker, 2015).

\section{Limitations}


Participants recruited from 'VirPed' and Twitter used these media platforms to promote awareness of non-offending paedophiles, and declared their attraction openly online, thus excluding people struggling to accept their paedophilia and those who hide their attractions (Goode, 2010; Cacciatori, 2017). Additionally, the researcher was unable to confirm the participants' non-offending statuses. As Walker (in press) emphasised, with a study offering minimal benefits to the respondent for participation, the likelihood of an offender purposefully taking part reduces. Projects employing IPA acknowledge that the data analysis is entirely dependent on the researcher's understanding of the transcripts, preconceptions and experiences (Norris, 1997). Whilst accepting that removing the researcher's preconceptions is “neither possible nor desirable" (Galdas, 2017, p.2), reflexive journaling and transparent theme construction were attempts to reduce the impact of these preconceptions on the analysis. Acknowledging the sample size, this study was exploratory in nature and relied upon a purposive, selective and therefore small sample. Nonetheless, further research would benefit from increasing the present study's sample size, to produce more generalizable results.

\section{Conclusion}

Acceptance of deviant interests is an under-researched area of sexual offending. As paedophilic offenders report significant internal conflict between self-acceptance and societal intolerance of paedophilia (Walton \& Duff, 2017), the area of acceptance is worth further investigation for both research and practical implications. Prison-based treatment programs for paedophilic child sex offenders do not cover "the complexity of this task" (Blagden et al, 2017, p.10) and reflections of the present sample suggest community-based services are lacking in the same respect. Current therapeutic intervention was seen as repressive by the 
sample, and if confirmed with a larger sample, this warrants further research into acceptance of paedophilic sexuality, and whether this would encourage sexual selfregulation and adaptive emotional and behavioural management (Hanson, 2010). Acceptance and Commitment Therapy (ACT; Hayes, Strosahl, \& Wilson, 1999) promotes open acknowledgement of personal difficulty and considers how suppressing any feelings only increases the frequency of them, and is currently being evaluated for use in the UK's first 'Prevention Project' (United Kingdom Council for Psychotherapy, 2018). It is important to note, that acceptance of paedophilia does not equate to acceptance of sexual behaviour with a child, as previous groups of paedophiles attempted to endorse in the 1970s (de Castella \& Heyden, 2014). Thus, the solution to the acceptance 'dilemma' may lie in striking a balance between sufficient acceptance to extinguish self-hatred amongst non-offenders, and ensuring that offending behaviour is not promoted.

\section{Implications for Practice:}

- Novel areas requiring further research and investigation are noted, which, if completed with a larger sample, could determine the wider breadth and relevance of the issues raised within the present sample, to this community.

- Larger samples of individuals from similarly stigmatised and isolated groups may be encouraged to take part in similar applied research.

\section{$\underline{\text { References }}$}

Becker, H.S. (1963) Outsiders. Studies in the Sociology of Deviance. NY: The Free Press. 
Beier, K.M., Ahlers, C.J., Goecker, D., Neutze, J., Mundt, I.A., Hupp, E., \& Schaefer, G.A. (2009) "Can pedophiles be reached for primary prevention of child sexual abuse? First results of the Berlin Prevention Project Dunkelfeld (PDD)", The Journal of Forensic Psychiatry \& Psychology, 20(6), pp. 851-867

Beier, K.M., Grundmann, D., Kuhle, L.F., Scherner, G., Konrad, A., \& Amelung, T. (2015) "The German Dunkelfeld Project: A Pilot Study to Prevent Child Sexual Abuse and the Use of Child Abusive Images", The Journal of Sexual Medicine, 12(2), pp. 529-542.

Berlin, F.S. (2014) "Pedophilia and DSM-5: The Importance of Clearly Defining the Nature of a Pedophilic Disorder". Journal of the American Academy of Psychiatry and the Law, 42(4), pp. 404-407

Blagden, N.J., Mann, R., Webster, S., Lee, R., \& Williams, F. (2017) “It’s Not Something I Chose You Know": Making Sense of Pedophiles' Sexual Interest in Children and the Impact on Their Psychosexual Identity. Sexual Abuse: A journal of research and treatment, 30(6), pp. 1-27.

Bunting, L., Lazenbatt, A., \& Wallace, I. (2010) "Information Sharing and Reporting Systems in the UK and Ireland: Professional Barriers to Reporting Child Maltreatment Concerns". Child Abuse Review, 19(3), pp. 187-202.

Cacciatori, H. (2017) The Lived Experiences of Men Attracted to Minors and Their Therapy-Seeking Behaviours (doctoral dissertation). Walden University, Minneapolis, MN.

Cantor, J.M., \& McPhail, I.V. (2016) "Non-offending Pedophiles”. Current Sex Health Report, 8(3), pp. 121-128.

Carter, N., Bryant-Lukosius, D., DiCenso, A., Blythe, J., \& Neville, A.J. (2014) "The Use of Triangulation in Qualitative Research". Oncology Nursing Forum, 41(5), pp. 545-549.

Criminal Justice and Public Order Act 1994 (2018) Available at https://www.legislation.gov.uk/ukpga/1994/33/section/84 (accessed 12 June 2018)

de Castella, T., \& Heyden, T. (2014) How did the pro-paedophile group PIE exist openly for 10 years? Available at https://www.bbc.co.uk/news/magazine-26352378 (accessed 14 June 2018)

Finkelhor, D. (1984) Child Sexual Abuse: New Theory and Research. New York: Free Press.

Freimond, C.M. (2013) Navigating the stigma of pedophilia: the experiences of nine minor-attracted men in Canada (master's thesis) Simon Fraser University, Vancouver, Canada.

Galdas, P. (2017) "Revisiting bias in qualitative research: Reflections on its relationship with funding and impact". International Journal of Qualitative Methods, 16(1), pp. 1-2. 
Gee, D., Ward, T., \& Eccleston, L. (2003) "The function of sexual fantasies for sexual offenders: A preliminary model”. Behaviour Change, 20(1), pp. 44-60.

Gilbert, F., \& Focquaert, F (2015) "Rethinking responsibility in offenders with acquired paedophilia: punishment or treatment?" International Journal of Law and Psychiatry, 38, pp. 51-60.

Goode, S. (2010) Understanding and addressing adult sexual attraction to children. London, England: Routledge.

Gerwinn, H., Weiß, S., Tenbergen, G., Amelung, T., Födisch, C., Pohl, A., Massau, C., Kneer, J., Mohnke, S., Kärgel, C., Wittfoth, M., Jung, S., Drumkova, K., Schiltz, K., Walter, M., Beier, K.M., Walter, H., Ponseti, J., Schiffer, B., \& Kruger, T.H.C. (2018) "Clinical characteristics associated with paedophilia and child sex offender - Differentiating sexual preference from offence status.” European Psychiatry, 51, pp. 74-85.

Grayson, J. (2016) Preventing Child Abuse: How to Work with Paedophiles to Stop the First Crime From Happening. Available at https://www.huffingtonpost.co.uk/julietgrayson/child-abuse-paedophilia_b_11684296.html (accessed 01 July 2018)

Hayes, S.C., Strosahl, K.D. \& Wilson, K.G. (1999) Acceptance and Commitment Therapy: An Experiential Approach to Behavior Change. New York: Guilford Press

Hanson, R. K. (2010) "Dimensional measurement of sexual deviance". Archives of Sexual Behavior, 39(2), pp. 401-404.

Hatzenbuehler, M.L. (2009) "How does sexual minority stigma "get under the skin"? A psychological mediation framework". Psychological Bulletin, 135(5), pp. 707-730.

Houtepen, J.A.B.M., Sijtsema, J.J., \& Bogaerts, S. (2016) "Being Sexually Attracted to Minors: Sexual Development, Coping with Forbidden Feelings, and Relieving Sexual Arousal in Self-Identified Pedophiles". Journal of Sex and Marital Therapy, 42(1), pp. 48-69.

Jahnke, S., Schmidt, A.F., Geradt, M., \& Hoyer, J. (2015) "Stigma-Related Stress and Its Correlates Among Men With Pedophilic Sexual Interests", Arch Sex Behav, 44(8), pp. 2173-2187.

Levine, J.A., \& Dandamudi, K. (2016) "Prevention of Child Sexual Abuse by Targeting Pre-Offenders before First Offense". Journal of Child Sexual Abuse, 25(7), pp. 719-737.

Long, T., \& Johnson, M. (2000) "Rigour, reliability and validity in qualitative research". Clinical Effectiveness in Nursing, 4(1), pp. 30-37.

Morse, J.M., Barrett, M., Mayan, M., Olson, K., \& Spiers, J. (2002) "Verification Strategies for Establishing Reliability and Validity in Qualitative Research". International Journal of Qualitative Methods, 1(2), pp. 13-22. 
Müller, K., Curry, S., Ranger, R., Briken , P., Bradford, J., \& Fedoroff, J.P. (2014) "Changes in sexual arousal as measured by penile plethysmography in men with pedophilic sexual interest". Journal of Sexual Medicine, 11(5), pp. 1221-1229

Noble, H. \& Smith, J. (2015) "Issues of validity and reliability in qualitative research". Evidenced Based Nursing, 18(2), pp. 34-35.

Norris, N. (1997) "Error, bias and validity in qualitative research". Educational Action Research, 5(1), pp. 172-176.

Rosenmann, A., \& Safir, M.P. (2006) "Forced Online: Push Factors of Internet Sexuality: A Preliminary Study of Online Paraphilic Empowerment". Journal of Homosexuality, 51(3), pp. 71-92.

Seto, M.C. (2012) "Is pedophilia a sexual orientation"? Archives of Sexual Behavior, 41(1), pp. 231-236.

Sheldon, K., \& Howitt, D (2010) "Sexual fantasy in paedophilic offenders: Can any model explain satisfactorily new findings from a study of Internet and contact sexual offenders?" Legal and Criminological Psychology, 13(1), pp. 137-158.

Smith, J. A., Jarman, M., \& Osborn, M. (1999) Doing interpretative phenomenological analysis. In: Murray, M \& Chamberlain, K (Ed.), Qualitative Health Psychology: Theories and methods. London: Sage, pp. 219-240.

Smith, J. A., \& Osborn, M. (2008) "Interpretative Phenomenological Analysis." In Smith, J (Ed.) Qualitative Psychology: A Practical Guide to Research Methods. London: Sage, pp. 53-80

Smith, J.A., Flowers, P., \& Larkin, M. (2012) Interpretive Phenomenological Analysis: Theory, Method, and Research. London: Sage.

Smith, J.A., \& Osborn, M. (2015) "Interpretative phenomenological analysis as a useful methodology for research on the lived experience of pain." British Journal of Pain, 9(1), pp. 41-42.

Stiels-Glenn, M. (2010) “The availability of outpatient psychotherapy for paedophiles in Germany". Recht \& Psychiatrie, 28(2), pp. 74-80

Theaker, E.A. (2015) Reframing the non-offending pedophile to combat child sexual abuse: a content analysis of public response to Luke Malone's "Help Wanted" (master's thesis) Bothell, University of Washington, Washington

United Kingdom Council for Psychotherapy (2018) The Safer Living Foundation. Retrieved from https://www.psychotherapy.org.uk/safer-living-foundation/

Walker, A. (in press) Understanding Resilience Strategies Among Minor-Attracted Individuals (Doctoral dissertation). City University of New York, NY, USA. 
Walton, J.S. (2013) An investigation into current issues in the treatment of men who sexually abuse children (doctorate thesis). University of Nottingham, Nottingham, UK.

Walton, J.S., \& Duff, S. (2017) 'I'm not homosexual or heterosexual, I'm paedosexual": exploring sexual preference for children using interpretive phenomenology". Journal of Forensic Practice, 19(2), pp. 151-161. 
Table 1: Participant demographics

\begin{tabular}{cllll}
\hline Participant & Age & $\begin{array}{l}\text { Age of } \\
\text { Attraction }\end{array}$ & $\begin{array}{l}\text { Gender of } \\
\text { Attraction }\end{array}$ & $\begin{array}{l}\text { Exclusive } \\
\text { attraction }\end{array}$ \\
\hline 1 & 23 & $2-13$ years & Boys & Yes \\
2 & 27 & $\begin{array}{l}5 \text { years - } \\
\text { prepubescent }\end{array}$ & Girls & No \\
& & $\begin{array}{l}7-9 \text { years (girls) } \\
9-13 \text { years } \\
\text { (boys) }\end{array}$ & Girls and Boys & No \\
& 54 & & & \\
\hline
\end{tabular}


Table 2: Themes and Subthemes

\begin{tabular}{lll}
\hline $\begin{array}{l}\text { Paedophilia as more than } \\
\text { sexuality }\end{array}$ & $\begin{array}{l}\text { Acceptance leads to } \\
\text { management }\end{array}$ & Barriers to support \\
\hline Sensuality and sociality & Repression is maladaptive & Inaccessibility \\
$\begin{array}{l}\text { These are my feelings, not my } \\
\text { actions }\end{array}$ & Hierarchy of consequences & Distrust of professionals \\
& & \\
\hline
\end{tabular}

